\title{
Comparing the Effect of Fuel/Air Interactions in a Modern High-Speed Light-Duty Diesel Engine
}

\author{
Felix Leach, Riyaz Ismail, Martin Davy \\ University of Oxford \\ Adam Weall, Brian Cooper \\ Jaguar Land Rover Ltd
}

Copyright $\odot 2017$ SAE International

\begin{abstract}
Modern diesel cars, fitted with state-of-the-art aftertreatment systems, have the capability to emit extremely low levels of pollutant species at the tailpipe. However, diesel aftertreatment systems can represent a significant cost, packaging and maintenance requirement. Reducing engine-out emissions in order to reduce the scale of the aftertreatment system is therefore a high priority research topic. Engine-out emissions from diesel engines are, to a significant degree, dependent on the detail of fuel/air interactions that occur in-cylinder, both during the injection and combustion events and also due to the induced air motion in and around the bowl prior to injection.
\end{abstract}

In this paper the effect of two different piston bowl shapes are investigated. Experiments are performed in a single-cylinder engine fitted with a production cylinder head and fuel injector in order to quantify the effect of the bowl shape and spray targeting - varied by varying the injector nozzle tip protrusion-on emissions and fuel consumption. Multi-dimensional CFD modelling is used to detail the effect of these geometry changes on the in-cylinder flow and fuel/air mixing processes thereby guiding the interpretation and understanding of the experimental results. The results suggest that improvements in engine-out emissions, as well as fuel consumption, may be obtained from current diesel engines by the careful matching of combustion system geometry with fuel injection hardware and strategy, and that an integrated approach with experimental and numerical studies working in parallel is essential to maximise these benefits.

\section{Introduction}

Diesel engines are widespread in light-duty vehicles in the worldwide market accounting for over $50 \%$ of all 2015 registrations in Europe and India [1]. Modern diesels, fitted with advanced aftertreatment systems, have the potential to emit very low levels of pollutants in the tailpipe; however, the required aftertreatment devices add significant complexity and cost to the vehicle - in the region of $\$ 1500$ per vehicle [2]. Furthermore, the costs of diesel aftertreatment necessarily extend into vehicle operation. Currently, the most commonly employed aftertreatment devices for diesel engines are; Diesel Oxidation Catalysts (DOCs) for hydrocarbon control, Diesel Particulate Filters (DPFs) for Particulate Matter (PM) control, and selective catalytic reduction (SCR) for $\mathrm{NO}_{\mathrm{x}}$ control. DPFs require

Page 1 of 10 periodic regeneration to remove trapped $\mathrm{PM} /$ soot with typical operating strategies for DPF regeneration resulting in fuel economy penalties of between $1 \%$ and $3 \%$ [3]. SCR devices require a continuous supply of Diesel Exhaust Fluid (DEF) — an aqueous solution of urea- to operate, necessitating constant system monitoring.

It is clearly of significant benefit to reduce emissions formation incylinder in order to lower the burden on the aftertreatment system, which should in turn bring down its associated cost, packaging constraints and maintenance requirements. Engine-out emissions are dependent on the detail of the fuel/air interactions in cylinder, before and during combustion. Diesel combustion initiates in locally rich zones (despite the overall mixture being lean) and at relatively low temperature causing large quantities of soot to be produced. The subsequent diffusion phase of diesel combustion is nearer to stoichiometric and at high temperature, leading to the in-cylinder oxidation of some of the soot and the formation of $\mathrm{NO}_{\mathrm{x}}$.

It has been shown that increasing air entrainment into the injected fuel leads to a reduction in soot emissions - albeit typically at the cost of increased $\mathrm{NO}_{\mathrm{x}}$ emissions - and an improvement in efficiency $[4,5]$. Increasing fuel injection pressure and the use of multiple injection events have been shown to increase air entrainment and mixing into the spray [6-9]. Fuel/air mixing and air entrainment is also affected by the interaction of the spray with the in-cylinder charge and combustion chamber geometry. In particular, the targeting of the spray with respect to the lip of the piston bowl will influence the local equivalence ratios in the bowl and the squish region $[10,11]$; combustion chamber heat transfer will also be affected $[12,13]$. Piston bowl shape will also have an effect on emissions and fuel consumption for similar reasons [13-15]. Previous studies $[12,16,17]$ have shown that a stepped piston bowl can reduce fuel consumption, soot, and $\mathrm{CO}$ emissions, compared to a conventional bowl.

With respect to spray targeting in a production engine, the chosen solution must not only provide low emissions and good performance at the selected design point, but it must also provide sufficient robustness against variance from that point. In this work we examine the sensitivity of the emissions and performance of a modern turbocharged, high-speed, light-duty diesel engine to a minor change in fuel spray targeting effected by a $0.5 \mathrm{~mm}$ change in injector nozzle tip protrusion (NTP) as well as a conventional bowl shape and a 
stepped bowl shape. Physical experiments are performed in a recently commissioned state-of-the-art single-cylinder diesel test facility. The experiments are supported by 3 -dimensional numerical modeling studies performed in a well-established commercially available CFD software package. The simulation results are used to explain the trends seen in the experimental results.

\section{Experimental methodology}

\section{Engine}

A single cylinder diesel engine capable of running up to $4400 \mathrm{rpm}$ supplied by Jaguar Land Rover has been used for this work. The engine has a Ricardo Hydra base, and the combustion system, cylinder head, and geometry are all the same as the Jaguar Land Rover AJ200D "Ingenium" engine [18]. A production standard fuel injection system is used, with an 8 -hole injector. Table 1 shows the engine specification. TDC measurements were very carefully taken in the engine in order to ensure that all of our indicated data (for example IMEP) was at the highest accuracy; TDC is measured using an AVL428 probe accurate to $\pm 0.1 \mathrm{CAD}$.

Table 1: Specifications of the single-cylinder diesel engine.

\begin{tabular}{|l|l|}
\hline Bore $\times$ Stroke & $83 \times 92.4 \mathrm{~mm}$ \\
\hline Displacement & $500 \mathrm{~cm}^{3}$ \\
\hline Valves per Cylinder & 2 intake, 2 exhaust \\
\hline Compression Ratio & $15.4: 1$ \\
\hline Fuel Pressure & $400-1800$ bar \\
\hline Injector & Production 'Ingenium' engine 8-hole injector \\
\hline
\end{tabular}

\section{Instrumentation}

A 57kW VASCAT AC dynamometer and ABB Power Electronics, controlled by a "Cadet" engine control system supplied by Sierra CP engineering, drive the engine. The engine oil and coolant is controlled with a Sierra CP conditioning rig, which controls the oil temperature to $\pm 1{ }^{\circ} \mathrm{C}$ and the coolant temperature to $\pm 2{ }^{\circ} \mathrm{C}$.

The inlet air is conditioned using an external boost rig. Two air compressors ( $29 \mathrm{~kW}$ in total) supply air to the rig which through the means of a Cadet controlled dump valve regulates the pressure to the demanded value (with an accuracy of $\pm 0.5 \%$ ). The compressors are capable of supplying sufficient air for full speed running at $4.5 \mathrm{bar}$ abs. Separate inlet air heating (using an OSRAM Sylvania $10 \mathrm{~kW}$ heater) and cooling (using an International Celsius $15 \mathrm{~kW}$ chiller) controls inlet air temperature to $\pm 1{ }^{\circ} \mathrm{C}$. This air is passed through a 50L smoothing tank before any EGR is inserted just upstream of a $1 \mathrm{~L}$ mixing plenum.

Exhaust back pressure is closed-loop controlled by Cadet using a back pressure valve mounted just downstream of a $25 \mathrm{~L}$ smoothing tank (again used to reduce the pulsations found in single cylinder engine exhausts). EGR (a high pressure EGR system is used) is taken from the smoothing tank, and passed through a production standard AJV6D EGR cooler and control valve, before being inserted into the inlet manifold, upstream of the $1 \mathrm{~L}$ smoothing plenum, to ensure that the EGR is well mixed.
The two inlet ports, the exhaust port, and the cylinder are all fitted with Kistler high-speed pressure transducers. This enables precise boundary conditions to be set in the CFD as well as facilitating detailed analysis of the in-cylinder pressure trace to enable indicated values to be used for fuel consumption, etc. These indicated values can be used to map data back onto the multi-cylinder engines and make the data from this single cylinder engine much more widely applicable.

Fuel flow is measured using a Sierra CP FuelTrak 1000 gravimetric fuel weigher. This can measure the fuel flow to $\pm 0.05 \%$ of reading, $\pm 0.03 \mathrm{~g}$. The accuracy of the indicated specific fuel consumption (ISFC) measurements is a combination of the accuracy of our measurement of fuel flow and of IMEP. ISFC was calculated based on a mean of $18 \times 10 \mathrm{~s}$ samples of fuel flow over a three minute log, using an updating IMEP from AVL indicom - datalogging and combustion analysis software. This gives an accuracy in ISFC at the most demanding condition (1500/6.8) of $\pm 1.5 \%$.

Exhaust emissions are measured by a Horiba MEXA-ONE emissions analyser and an AVL415S smoke meter. The MEXA-ONE measures $\mathrm{CO}_{2}$ (both in the inlet and exhaust for EGR rate calculations), $\mathrm{CO}$, THC, $\mathrm{NO}, \mathrm{NO}_{2}, \mathrm{NO}_{\mathrm{x}}$, and $\mathrm{O}_{2}$ to a repeatability of $0.5 \%$ of full scale for all gases. Lambda $(\lambda)$ is calculated using the Brettschneider method [19] and the EGR rate is calculated using the intake and exhaust $\mathrm{CO}_{2}$ levels. In addition to the MEXA unit, an ETAS ES430 compatible lambda sensor was used to measure oxygen content in the exhaust and calculate $\lambda$, this was used as a cross-check to the MEXA derived lambda. The AVL415S is a standard smoke meter, sampling exhaust onto filter paper, and measuring the subsequent blackening with a reflectometer. The repeatability of this instrument is $\pm 5 \%$ of the measurement value or \pm 0.005 Filter Smoke number (FSN) (the higher value to be used) [20].

The engine is not fitted with a catalyst, nor a DPF, hence the emissions measured are raw engine out emissions, which are sampled approximately $1 \mathrm{~m}$ downstream from the exhaust back pressure valve at approximately atmospheric pressure.

A Pi Innovo M670 OpenECU is used for engine control. This ECU, based on a Jaguar Land Rover built Simulink model, offers full control of the fuel injection equipment, as well as the EGR and swirl valves fitted to the engine. The OpenECU is controlled by an ETAS INCA interface, which connects to Cadet through an ASAP3 link.

Cadet is set to $\log$ parameters at $1 \mathrm{~Hz}$, whereas high speed data acquisition is used for the four Kistler pressure transducers as well as a current clamp signal (and the TDC sensor when in use) using indicom, with a $0.1 \mathrm{CAD}$ resolution.

\section{Fuel}

The tests were run using an EN590 [21] B0 standard diesel. Table 2 shows the properties of the diesel tested.

Table 2: Diesel composition.

\begin{tabular}{|l|l|}
\hline Cetane Number & 53.0 \\
\hline Initial Boiling Point $\left({ }^{\circ} \mathrm{C}\right)$ & 171.4 \\
\hline Final Boiling Point $\left({ }^{\circ} \mathrm{C}\right)$ & 355.0 \\
\hline
\end{tabular}




\begin{tabular}{|l|l|}
\hline Aromatics $(\% \mathrm{~m} / \mathrm{m})$ & 25.1 \\
\hline Sulfur $(\mathrm{mg} / \mathrm{kg})$ & 6.5 \\
\hline FAME $(\% \mathrm{v} / \mathrm{v})$ & $<0.1$ \\
\hline
\end{tabular}

\section{CFD - numerical model}

Engine simulations were carried out with a commercially available CFD code allowing 3-dimensional modelling of multiphase incompressible/compressible, unsteady turbulent combusting flows.[22]

Combustion was modelled with the 3-Zone Extended Coherent Flame Model (ECFM3Z) [23] which incorporates mixing zones to the flamelet model to describe inhomogeneous turbulent premixed and non-premixed combustion. This is coupled with Tabulated Kinetic Ignition (TKI) to model auto-ignition [24].

The RNG k-epsilon model [25] was used to for turbulence closure. This widely used model accounts for the mean flow distortion on the dissipation rate allowing the resolution of rapid straining complex rotational flows.

A summary of all the sub-models used can be found in Table 3

Table 3: Sub-models used in CFD.

\begin{tabular}{|l|l|l|}
\hline \multirow{3}{*}{ Spray } & Breakup & KH-RT [26] \\
\cline { 2 - 3 } & Turbulent dispersion & O'Rourke [27] \\
\cline { 2 - 3 } & Collisions & NTC [28] \\
\cline { 2 - 3 } & Wall film & Kuhnke [29] \\
\hline Wall model & Heat transfer & Han \& Reitz [30] \\
\hline
\end{tabular}

The symmetry of the equispaced eight-hole injector was used to save on run-time by limiting the computational domain to a $45^{\circ}$ sector of the engine and running the model from IVC to just before EVO. Whilst the results will differ slightly from modelling of a complete geometry: due to the effect of valve crevices, global trends have been shown to be comparable [31]. Adaptive Mesh Refinement and Fixed Embedding (constant addition of cells in a particular region) of the injector were used to control mesh size during the cycle. Cell sizes varied from a maximum of $1.4 \mathrm{~mm}$ to a minimum of $0.175 \mathrm{~mm}$ allowing resolution of fine scale structures during spray and combustion. The computational domain at TDC is illustrated in Figure 1.

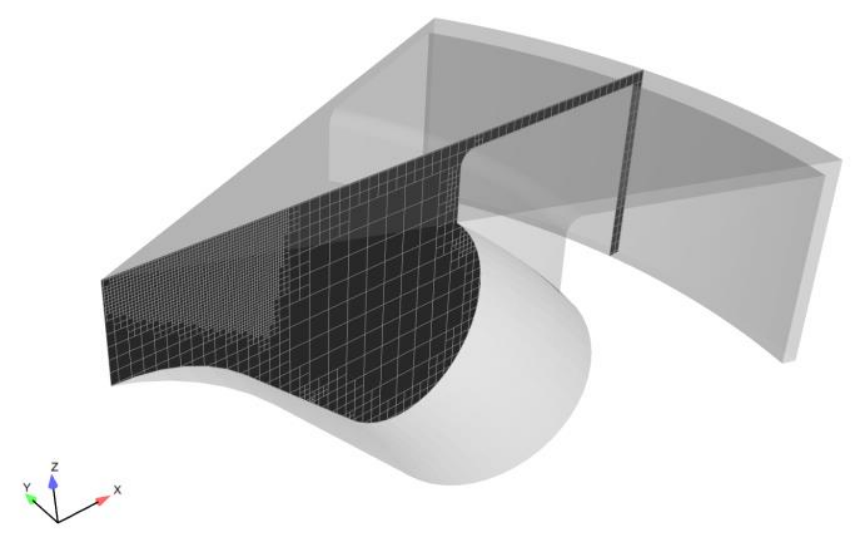

Figure 1. The computational domain used at TDC.

\section{CFD-validation}

The CFD model was validated at two test points. Figure 2 shows the in cylinder pressure for both points for the standard bowl with NTP 1. Overall, the predicted results show excellent agreement with experimental data. The minor differences seen, especially during the pilot burn can be attributed to the uncertainty in the rate of injection that was used in the CFD model and the use of a single component surrogate fuel. As an experimental rate of injection was not available, the injector flow rate used in the CFD model was computed from a 1D model of the test injector. Accuracy of the injection rate is hence sensitive to the structural elements of the injection system for which the model has accounted for.

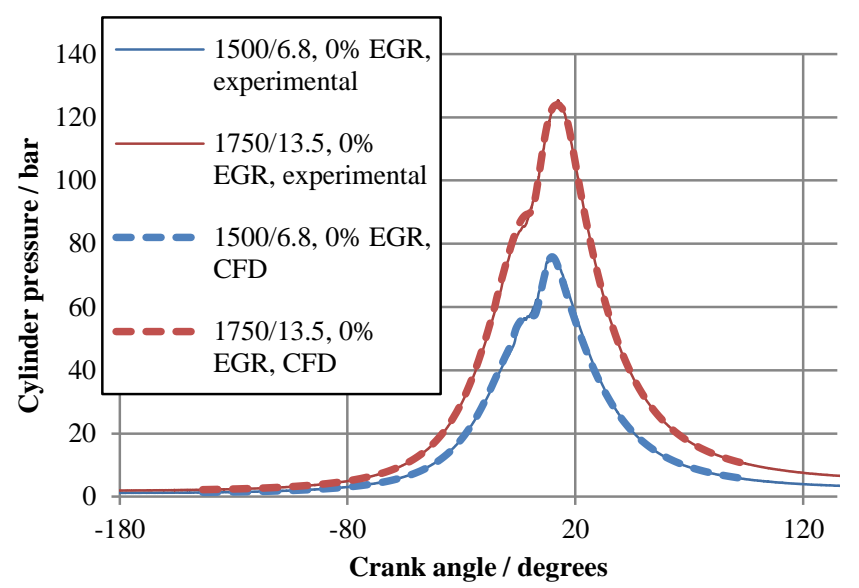

Figure 2. Comparison between CFD and experimental cylinder pressure traces validating the CFD used. An excellent match is observed.

The heat release computed by the CFD has also been compared with the experimentally measured heat release (in this case, both have been computed from $-25 \mathrm{CAD}$ to $135 \mathrm{CAD}$ ). Figure 3 shows that the agreement between the CFD and experimental results is excellent for the whole period calculated. This gives very high confidence in the CFD used in this work. 


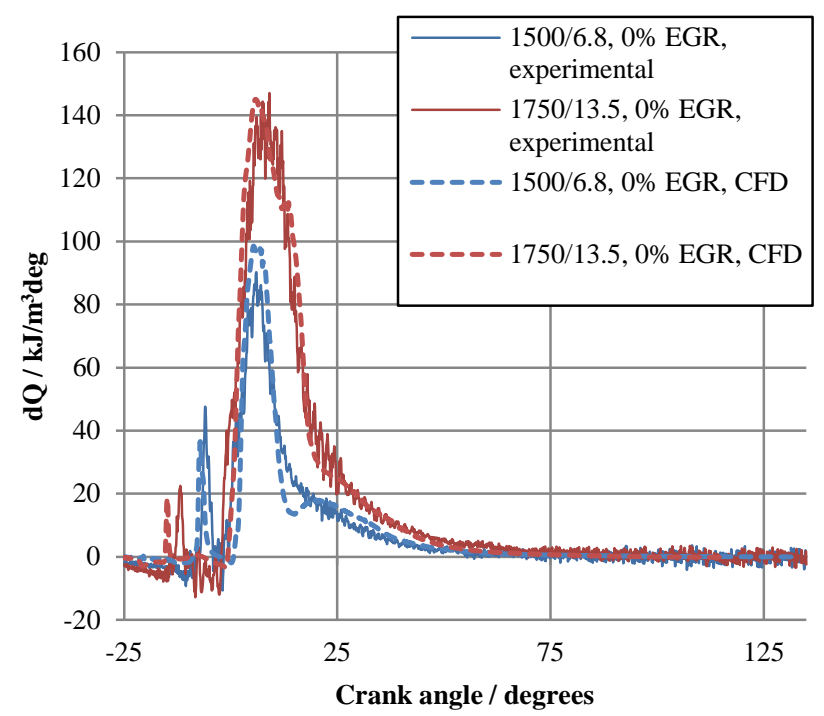

Figure 3. Comparison between CFD and experimental heat release validating the CFD used. Another excellent match is observed.

\section{Results and Discussion}

Throughout this work the spray targeting was varied by changing the Nozzle Tip Protrusion (NTP) of the injector by putting a different thickness washer on the base of the injector - this changed the NTP by $0.5 \mathrm{~mm}$. Two piston bowl shapes were tested, a reentrant bowl (standard) and a stepped bowl; the two bowl shapes are shown in Figure 4. The stepped bowl shape was chosen to be as close to the re-entrant bowl geometrically, as possible, whilst leaving compression ratio unaltered, It must be acknowledged that the heat transfer properties of the two pistons will be slightly different, with the lip on the stepped lip piston lying closer to the oil cooling gallery than the standard bowl.

\begin{tabular}{|l|l|}
\hline Stepped lip bowl & Standard bowl \\
\hline
\end{tabular}

Figure 4. Cross sections of the standard piston and stepped lip piston.

Each test point was measured for three minutes, and a mean of the logged data was taken. Each point was run at least three times over a series of days, non-sequentially, to ensure repeatability. All emissions readings have been rescaled by dividing by a nominal value - the same nominal value for all load points. All of the data is presented against $\mathrm{ISNO}_{\mathrm{x}}$, acting as an indicator of the EGR levels with values closest to 1 indicating no external EGR, and values closest to 0 indicating the maximum level of EGR tested.

The engine was run at two fixed speed/load operating points as shown in Table 4. The EGR rate was varied in five equal steps at a constant exhaust backpressure and inlet manifold pressure. The injection timing remained fixed for each test point, with a small pilot of fixed quantity. The engine load was set by varying the main injection quantity to match the desired IMEP, which was held constant through the EGR sweep.
Table 4: Engine operating points.

\begin{tabular}{|l|c|c|}
\hline Test point ID & $\mathbf{1 5 0 0 / 6 . 8}$ & $\mathbf{1 7 5 0 / 1 3 . 5}$ \\
\hline Engine speed (rpm) & 1500 & 1750 \\
\hline IMEP (bar) & 6.8 & 13.5 \\
\hline Inlet manifold pressure (barG) & 0.25 & 1.0 \\
\hline Exhaust backpressure (barG) & 0.45 & 1.4 \\
\hline Inlet air temperature $\left({ }^{\circ} \mathrm{C}\right)$ & \multicolumn{2}{|c|}{ Varies with EGR } \\
\hline Coolant and oil temperature $\left({ }^{\circ} \mathrm{C}\right)$ & \multicolumn{2}{|c|}{90} \\
\hline EGR levels (approx.) & $0-40 \%$ & $0-27 \%$ \\
\hline Fuel rail pressure (MPa) & 55 & 90 \\
\hline
\end{tabular}

Figure 5 shows the $\mathrm{NO}_{\mathrm{x}}$-Soot trade-off at the lowest load test point (1500/6.8) at the two different NTPs with the two different bowls. There is an improvement in the $\mathrm{NO}_{\mathrm{x}}$-Soot trade-off seen for NTP 2 particularly in the middle of the EGR sweep; however the results are insensitive to bowl shape. This improvement is consistent with better air entrainment and mixing. In addition with deeper NTP there will be less fuel able to get into the squish region, where the mixing and air utilization will be very poor - again leading to comparatively higher soot emissions at the shallower NTP.

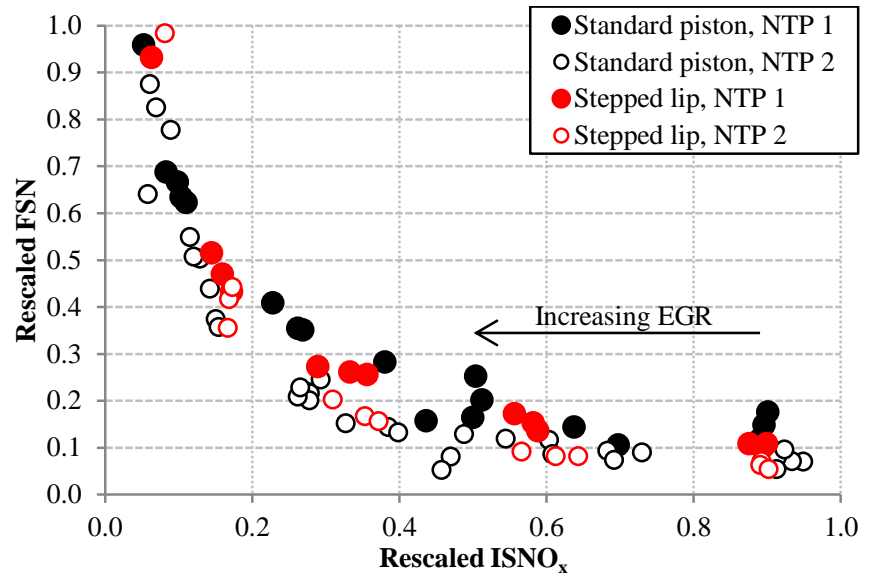

Figure 5. ISNO ${ }_{x}-$ FSN results at 1500/6.8, showing that overall there is an improved $\mathrm{ISNO}_{\mathrm{x}}$-FSN tradeoff at NTP 2 for both bowls, the difference between the two bowls is minimal suggesting mixing is improved with the increased NTP but that the bowl shape is less important.

Figure 6 shows the $\mathrm{NO}_{\mathrm{x}}$-Soot trade-off at $1750 / 13.5$ with the two bowls at the two different NTPs. Here it can be seen that there is a significant benefit across the whole range with the increased NTP for both bowls. At NTP 1 there is a slight benefit for the stepped lip piston over the standard piston, in the middle of the EGR range, however there is also a moderate increase in $\mathrm{ISNO}_{\mathrm{x}}$ with the stepped lip piston at both NTPs at $0 \%$ EGR (maximum ISNO ${ }_{x}$ ). Perhaps the higher engine load and speed are exaggerating the effects noted in 1500/6.8. The CFD results in Figure 16 (discussed later) demonstrate that there is increased mixing with increased NTP, and these engine results show that. 


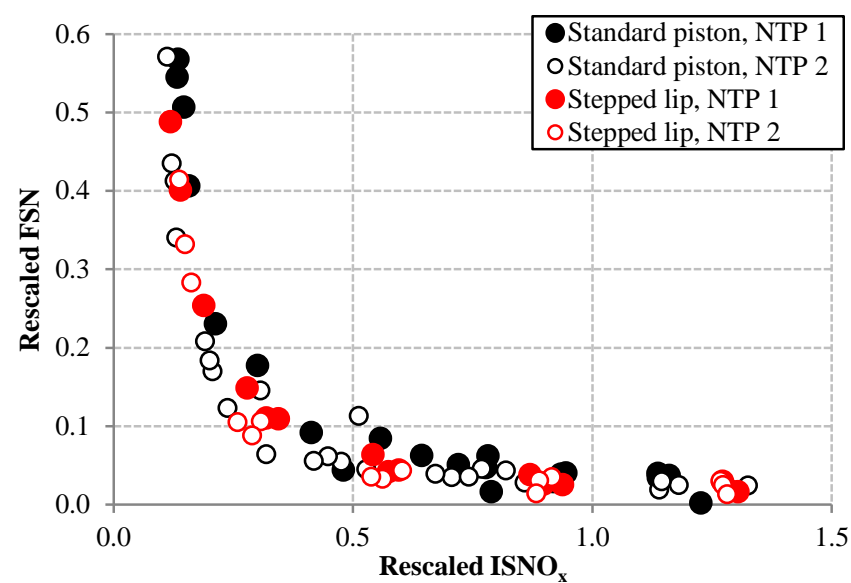

Figure 6. ISNO $\mathrm{X}_{\mathrm{x}}-\mathrm{FSN}$ results at 1750/13.5, showing a significant improvement across the EGR range with the increase in NTP, which would be seen with greater mixing at increased NTP. There is also a minor improvement with the stepped bowl compared to the standard bowl at NTP 1.

Figure 7 and Figure 8 show the ISCO results at both of the speed/load conditions tested. The same trends to those seen in the $\mathrm{NO}_{\mathrm{x}}-\mathrm{Soot}$ results (Figure 5 and Figure 6) are seen, suggesting that the improvement in $\mathrm{NO}_{\mathrm{x}}$-Soot tradeoff with increasing NTP is due to the improved mixing that this deeper NTP gives, as this increased mixing will also promote $\mathrm{CO} \rightarrow \mathrm{CO}_{2}$ conversion, which is seen here - the advantages of having less fuel in the squish region will also benefit this, as before. Here again, it can be seen that there is no difference in ISCO emissions with bowl shape.

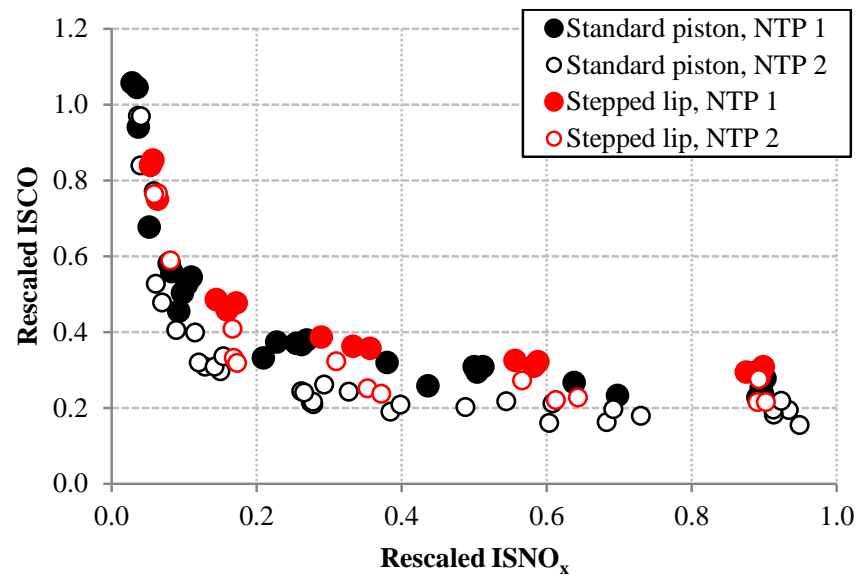

Figure 7: ISCO emissions at 1500/6.8. A clear reduction in ISCO can ben seen with increased NTP, bowl shape has little effect, this follows closely the FSN results in Figure 5 as would be expected and again suggests that mixing is improved with increased NTP.

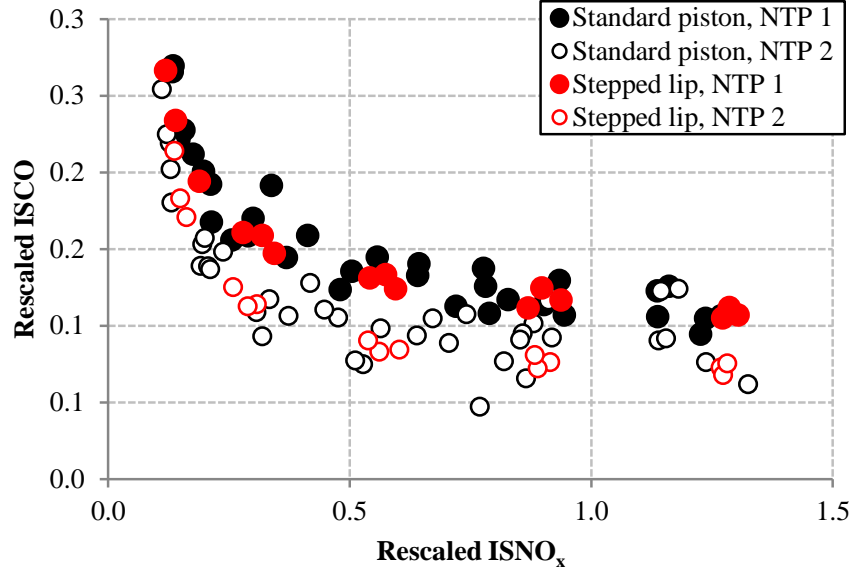

Figure 8: ISCO emissions at 1750/13.5. A clear reduction in ISCO can be seen with increased NTP, bowl shape has little effect, this follows the trends seen at 1500/6.8 and again suggests that mixing is improved with increased NTP.

Figure 9 shows the ISTHC emissions at 1500/6.8. Again, no difference is observed with bowl shape, but, particularly at higher levels of EGR (lower levels of ISNO ${ }_{\mathrm{x}}$ ), a decrease in ISTHC emissions is seen with deeper NTP. This again suggests that there is better mixing with increased NTP. Increased mixing will help the available oxygen (reduced at higher levels of EGR) reach the unburned fuel, promoting its oxidation.

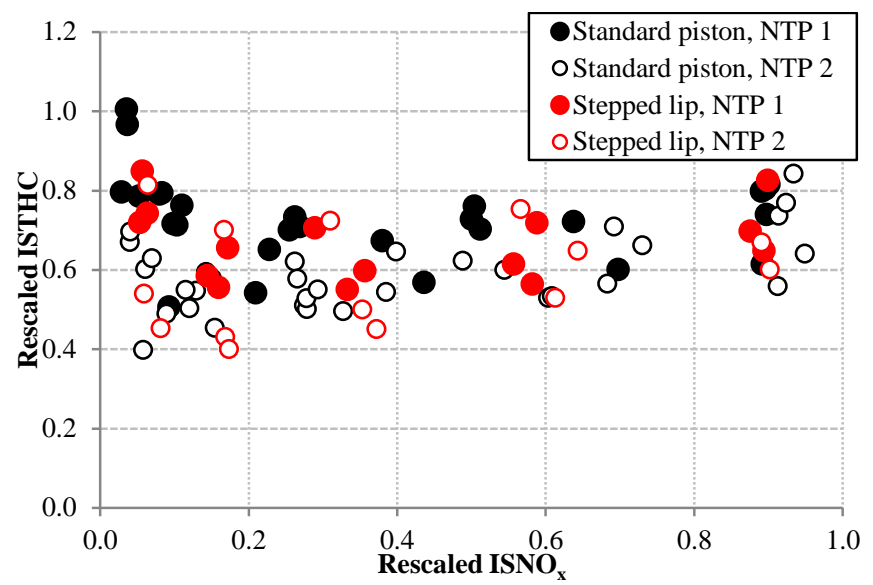

Figure 9: ISTHC emissions at 1500/6.8, a small decrease in THC emissions can be seen at high levels of EGR (low ISNO ${ }_{x}$ ) at NTP 2, once again suggesting better mixing at this deeper NTP.

Figure 10 show the ISTHC results at 1750/13.5. Here no difference is observed with bowl shape or NTP. It should be noted that overall ISTHC emissions are much lower, close to the detection limit of the instrument, and perhaps at this higher load/speed there is sufficient mixing anyway for the increase in NTP to make an immaterial difference to ISTHC emissions. 


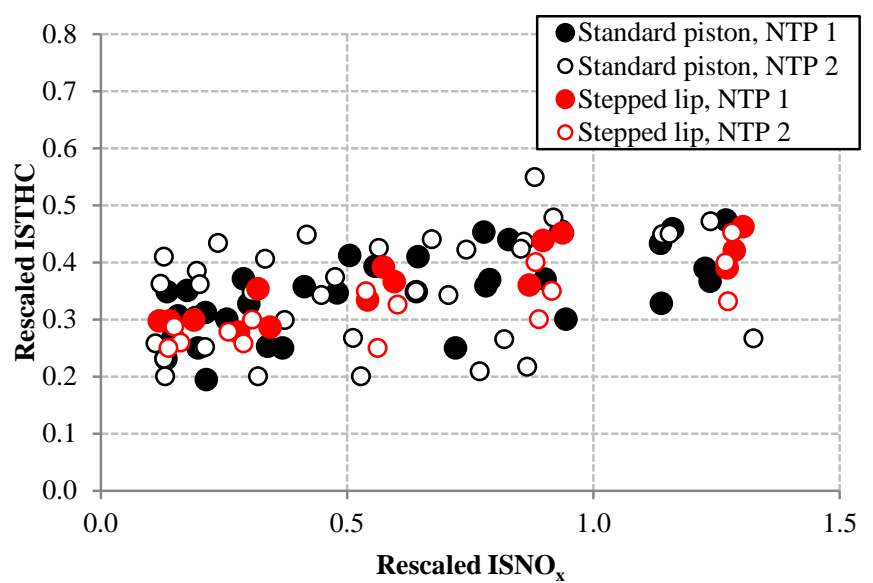

Figure 10 ISTHC emissions at 1750/13.5, no significant difference can be seen with NTP or bowl shape suggesting that there is sufficent mixing at $1750 / 13.5$ for the additional mixing caused by increasing NTP to be immaterial.

Figure 11 and Figure 12 show the ISFC at 1500/6.8 and 1750/13.5 respectively as EGR is varied with the two bowls and at the two NTPs. At both load conditions there is good repeatability and there is no variation in ISFC with bowl shape or NTP, showing that the ISFC is unaffected by these at this load condition. This demonstrates that the deeper NTP 2 will give the $\mathrm{NO}_{\mathrm{x}}$-Soot emissions benefit, without compromising fuel consumption

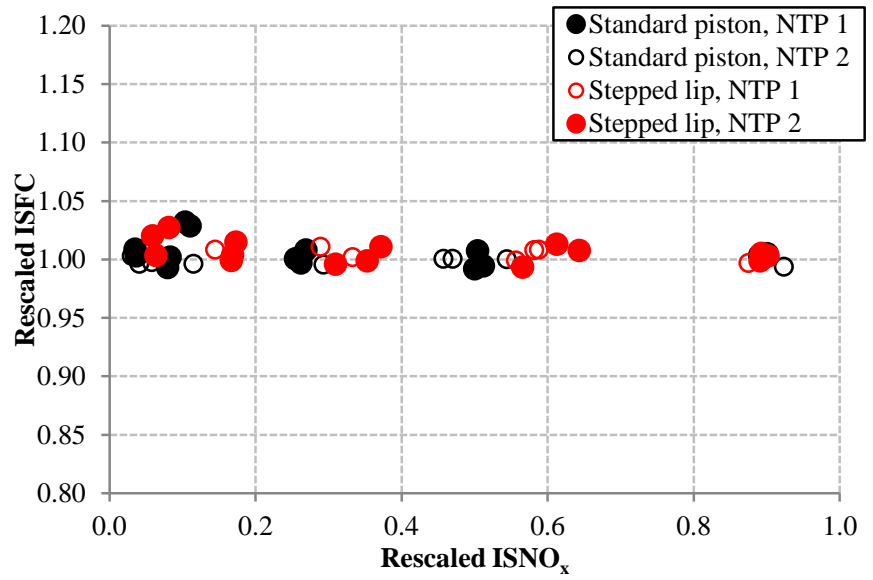

Figure 11. ISFC results at 1500/6.8, showing good repeatability, but no difference with NTP or bowl shape.

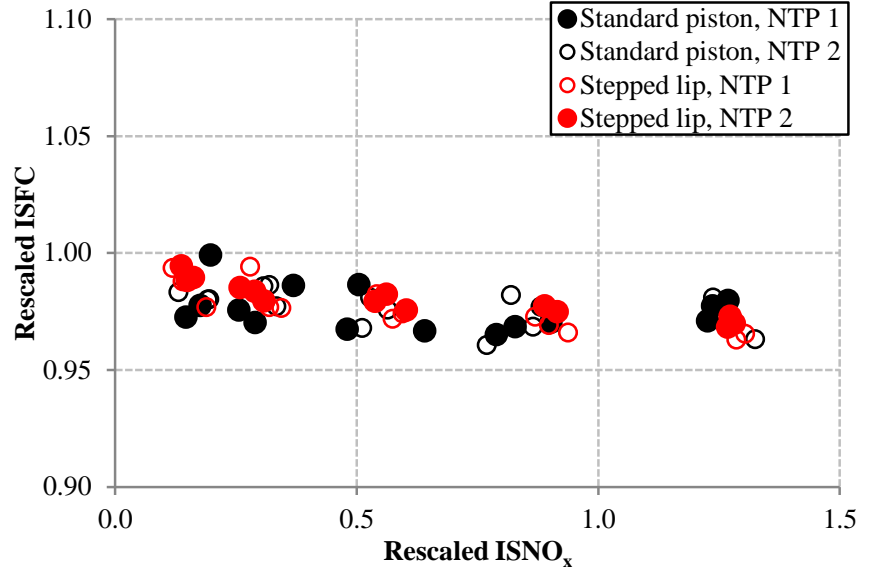

Figure 12. ISFC results at 1750/13.5, again showing good repeatability, but no difference with NTP or bowl shape.

Figure 13 shows the CA10, CA50, and CA90 variations with EGR for the two bowl shapes at the two different NTPs at 1500/6.8. The effect of fixed fuel injection timing can be seen with CA50 varying with EGR rate by about $2 \mathrm{CAD}$. The results suggest that the increase in NTP brings a very minor decrease in CA50 and a slight decrease in CA10 for the standard piston at $1500 / 6.8$. This shows that there is a slightly reduced ignition delay with the increased NTP. This difference increases with increasing EGR rate, suggesting that as the rate of EGR increases, the improved mixing is aiding fuel-air interactions. This is a consistently observed trend although there is some scatter in the data, which is consistent with the observation from CFD that there is better mixing with the increased NTP. At $1750 / 13.5$ this difference in CA10 and CA50 is not observed (Figure 14), again suggesting that there may be sufficient mixing at this higher load condition that the difference in NTP does not change the overall mixing.

Figure 13 and Figure 14 also show that the effect of the stepped lip is to increase the 50-90\% mass fraction burned (MFB) duration at both speed/load conditions. At 1500/6.8 it increases by around 6 CAD and at $1750 / 13.5$ it is increased by around $3 \mathrm{CAD}$ across the EGR range. This result is interesting as both Dahlstrom [12] and Busch [17] reported an almost exact opposite trend with a stepped piston at three part load points and 1500/9 respectively.

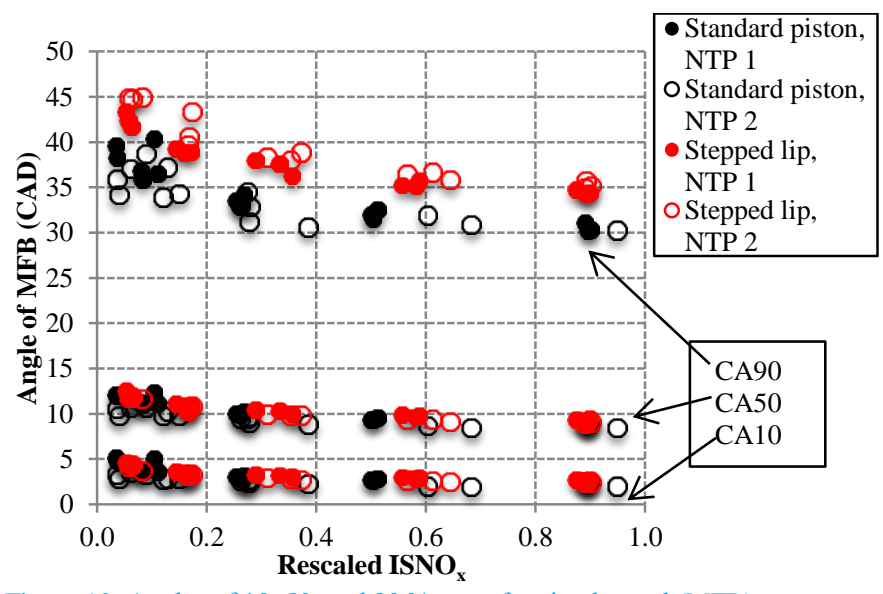

Figure 13: Angles of 10, 50, and $90 \%$ mass fraction burned (MFB) at 1500/6.8. A significant increase in 50-90\% MFB duration is noted for the 


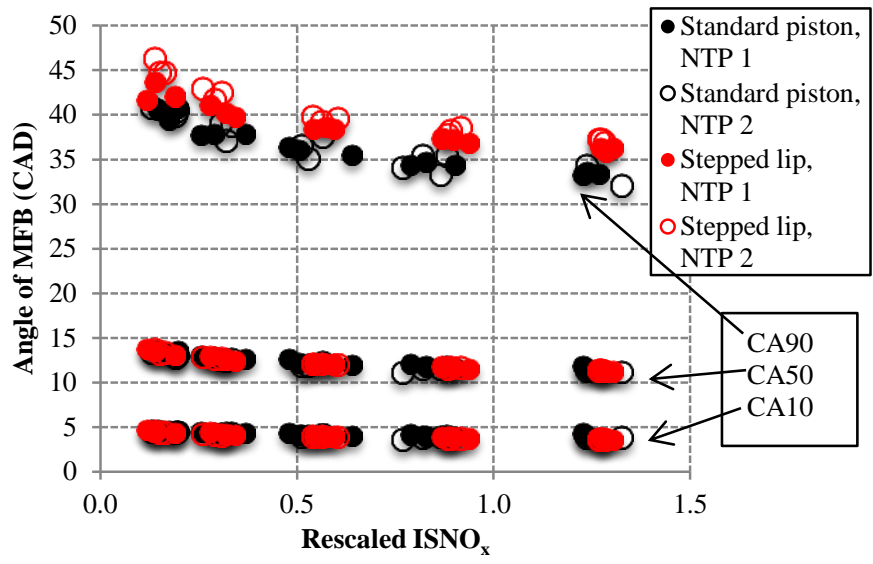

Figure 14: Angles of 10, 50, and $90 \%$ mass fraction burned (MFB) at $1750 / 13.5$. Again, no difference is seen in 10-50\% MFB duration, but the stepped lip piston shows an increase in 50-90\% MFB duration, with a slight increase with increased NTP for that piston.

Figure 15 and Figure 16 shows the in cylinder velocities from the CFD comparison between the two NTPs at 1500/6.8 and 1750/13.5. Particularly later in the combustion (30 CAD atdc), an increase in flow velocity can be seen inside the bowl with deeper NTP. The fuel is also being injected targeted closer to the high speed vortex seen inside the bowl. This would correspond to our hypothesis of improved mixing from the emissions results seen in Figure 5-Figure 10. Figure 17 shows the equivalence ratio distribution on an $X-Y$ cut plane at the same height as the piston crown at 1500/6.8. The improved mixing from increased NTP can clearly be seen in the bowl region where the equivalence ratio is locally higher but also covers a greater area of the bowl. It is clear that the increased NTP leads to improved mixing and this is leading to lower soot, $\mathrm{CO}$, and THC emissions, as would be expected. A difference in overall velocity levels is also observed between the two speed/load cases, with greater velocities seen across a larger part of the bowl at 1750/13.5 (note the different scales at $30 \mathrm{CAD}$ atdc with the peak velocity increased from 25 to $32 \mathrm{~m} / \mathrm{s}$ ) implying that there are fewer benefits to be gained from increasing mixing with increasing NTP, which is again reflected in the engine emissions results (Figure 10).

\begin{tabular}{|c|c|c|}
\hline Velocity & NTP 1 & NTP 2 \\
\hline 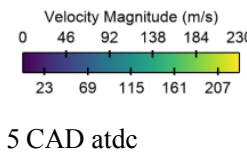 & & \\
\hline $\begin{array}{l}\text { Velocity Magnitude (m/s) } \\
15 \text { CAD atdc }\end{array}$ & & \\
\hline
\end{tabular}

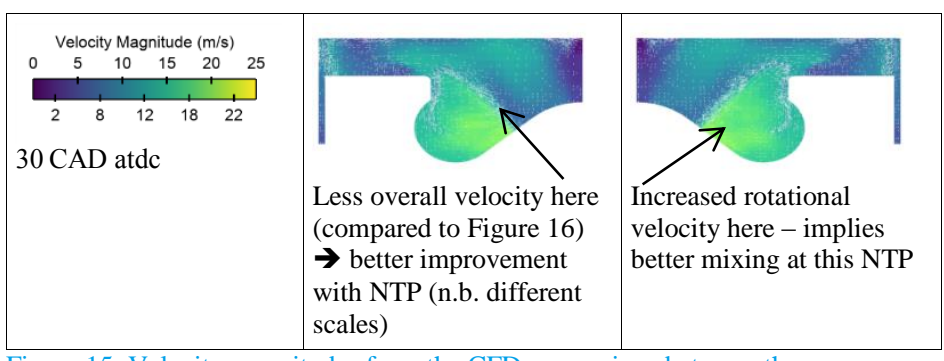

Figure 15: Velocity magnitudes from the CFD comparison between the standard piston at NTP 1 and NTP 2 at 1500/6.8.

\begin{tabular}{|c|c|c|}
\hline Velocity & NTP 1 & NTP 2 \\
\hline 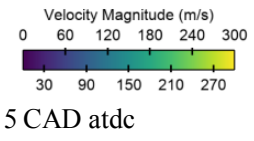 & & \\
\hline 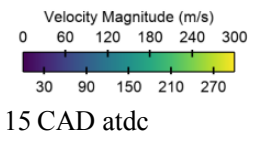 & & \\
\hline \begin{tabular}{l}
\multicolumn{5}{c}{$\begin{array}{c}\text { Velocity Magnitude }(\mathrm{m} / \mathrm{s}) \\
0 \\
0\end{array}$} \\
\end{tabular} & & $\begin{array}{l}\text { Increased rotational } \\
\text { velocity here - implies } \\
\text { better mixing }\end{array}$ \\
\hline
\end{tabular}

Figure 16: Velocity magnitudes from the CFD comparison between the standard piston at NTP 1 and NTP 2 at 1750/13.5.

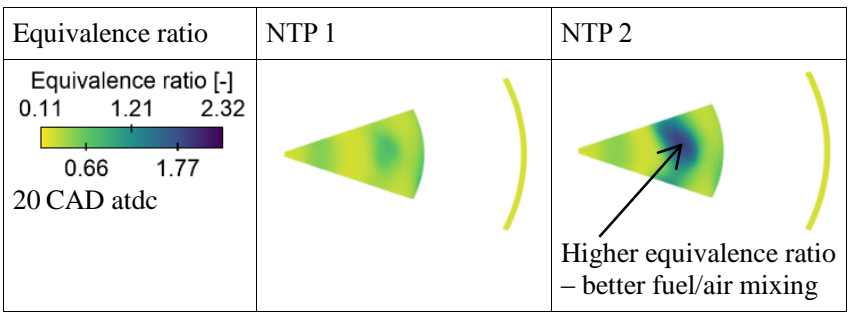

Figure 17: Equivalence ratios from the CFD comparison between the standard piston at NTP 1 and NTP 2 at 1500/6.8 on an X-Y cut plane.

Due to the surprising 50-90\% burn duration results observed in Figure 13 and Figure 14, it is of interest to use the CFD to investigate why this occurs. Figure 18 shows the temperature profiles in the combustion chamber for both of the bowl shapes at NTP 2 at $1750 / 13.5$. Initially the combustion is very similar between the two bowls - as far as $10 \mathrm{CAD}$ atdc little difference is observed, this agrees with the similar CA50 values observed for both bowls (Figure 13 and Figure 14). The effect of the lip can most clearly be seen at $15 \mathrm{CAD}$ atdc - here it can be seen that the lip is effectively "holding up" the flame, and it appears briefly to "stick" as it climbs the lip before moving horizontally across the top face of the piston. The effect is still visible at $30 \mathrm{CAD}$ atdc showing that this is a phenomenon which is affecting all of the combustion process and agreeing with the later CA90 values observed for the stepped bowl (Figure 13 and Figure 14). 
Part of the reason for the difference between the MFB results presented in this paper, compared to contrasting results [12,17] might be that here the bowl is a definite step in shape whereas both of the lips in $[12,17]$ have a much more angled shape, possibly allowing the flame front to move over it more easily.

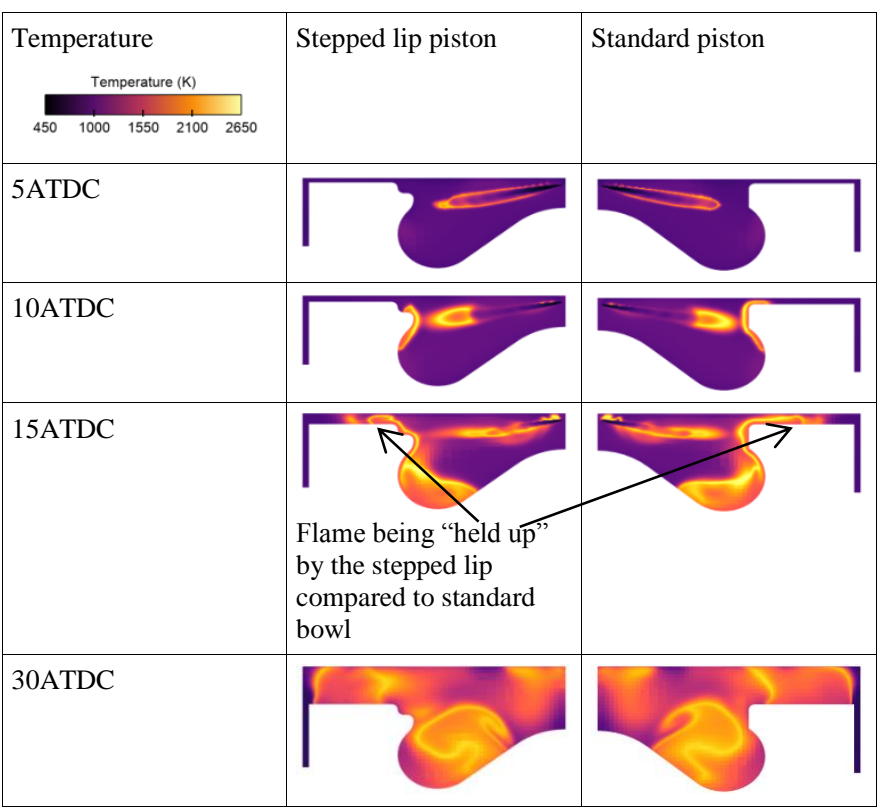

Figure 18: In cylinder temperatures from the CFD comparison between the standard and the stepped bowl piston at NTP 2 at 1750/13.5.

\section{Summary/Conclusions}

In order to meet increasingly stringent, non-powertrain specific emissions legislation, a focus on engine out emissions is needed in order that the aftertreatment systems do not become prohibitively expensive. Detailed understanding of fuel/air interactions is needed to achieve this. In this paper this has been undertaken by varying the nozzle tip protrusion of the fuel injector and the piston bowl shape to investigate the effect of fuel spray targeting on the fuel/air interactions and hence the emissions.

The results presented in this paper show that emissions are particularly sensitive to spray targeting. A change in NTP of $0.5 \mathrm{~mm}$ gave an improved $\mathrm{NO}_{\mathrm{x}}$-Soot tradeoff and a reduction in $\mathrm{CO}$ and $\mathrm{THC}$ emissions at both of the speed/load test points tested across an EGR sweep with no difference observed in ISFC, no differences were observed with these parameters with bowl shape. Differences in burn rate were also observed consistent with greater mixing at greater NTP. However here, bowl shape was an important factor with the stepped lip piston increasing 50-90\% MFB durations. CFD analysis showed that this was due to the stepped lip effectively holding up the flame. Future work could include optimising an injection strategy to make use of these flow differences in the stepped bowl (in this work the same strategy was used for both bowls).

The integrated approach with CFD has proven invaluable for understanding the engine results, with the differences in mixing and temperature fields providing good evidence for the emissions results observed. The CFD can also predict the heat release with great Page 8 of 10 accuracy, proving it as an invaluable tool for giving greater insights into experimentally observed phenomena.

\section{References}

1. ICCT, European Vehicle Market Statistics Pocketbook 2016/17. 2017.

2. ICCT, Estimated Cost of Emission Reduction Technologies for Light-Duty Vehicles. 2012.

3. Salvat, O., Marez, P., and Belot, G., Passenger Car Serial Application of a Particulate Filter System on a Common Rail Direct Injection Diesel Engine, SAE Technical Paper 2000-01-0473, 2000, doi:10.4271/2000-01-0473.

4. Ehleskog, R., Ochoterena, R., and Andersson, S., Effects of Multiple Injections on Engine-Out Emission Levels Including Particulate Mass from an HSDI Diesel Engine, SAE Technical Paper 2007-01-0910, 2007, doi:10.4271/2007-01-0910

5. Pickett, L.M. and D.L. Siebers, Soot in diesel fuel jets: effects of ambient temperature, ambient density, and injection pressure. Combustion and Flame, 2004. 138(1-2): p. 114-135.

6. Gill, K., Marriner, C., Sison, K., and Zhao, H., In-cylinder Studies of Multiple Diesel Fuel Injection in a Single Cylinder Optical Engine, SAE Technical Paper 2005-010915, 2005, doi:10.4271/2005-01-0915

7. Montgomery, D. and Reitz, R., Effects of Multiple Injections and Flexible Control of Boost and EGR on Emissions and Fuel Consumption of a Heavy-Duty Diesel Engine, SAE Technical Paper 2001-01-0195, 2001, doi:10.4271/2001-01-0195.

8. O'Connor, J. and M. Musculus, Post Injections for Soot Reduction in Diesel Engines: A Review of Current Understanding. SAE International Journal of Engines, 2013. 6(1): p. 400-421.

9. Han, Z., Uludogan, A., Hampson, G., and Reitz, R., Mechanism of Soot and NOx Emission Reduction Using Multiple-injection in a Diesel Engine, SAE Technical Paper 960633, 1996, doi:10.4271/960633.

10. Kook, S., Bae, C., Miles, P., Choi, D. et al., The Effect of Swirl Ratio and Fuel Injection Parameters on CO Emission and Fuel Conversion Efficiency for High-Dilution, LowTemperature Combustion in an Automotive Diesel Engine, SAE Technical Paper 2006-01-0197, 2006,

doi:10.4271/2006-01-0197.

11. Dakhore, R., Gandhi, N., Gokhale, N., Aghav, Y. et al., Effect of Piston Cavity Geometry on Combustion, Emission and Performance of a Medium Duty DI Diesel Engine, SAE Technical Paper 2015-26-0198, 2015, doi:10.4271/2015-26-0198.

12. Dahlstrom, J., Andersson, O., Tuner, M., and Persson, H., Experimental Comparison of Heat Losses in Stepped-Bowl and Re-Entrant Combustion Chambers in a Light Duty Diesel Engine, SAE Technical Paper 2016-01-0732, 2016, doi:10.4271/2016-01-0732.

13. Fridriksson, H., Tuner, M., Andersson, O., Sunden, B. et al., Effect of Piston Bowl Shape and Swirl Ratio on Engine Heat Transfer in a Light-Duty Diesel Engine, SAE Technical Paper 2014-01-1141, 2014, doi:10.4271/201401-1141.

14. Lee, J., Lee, S., Kim, J., and Kim, D., Bowl Shape Design Optimization for Engine-Out PM Reduction in Heavy Duty 
Diesel Engine, SAE Technical Paper 2015-01-0789, 2015, doi:10.4271/2015-01-0789.

15. Nishida, K., Ogawa, T., Hashizume, T., Ishiyama, S. et al., Small Bore Diesel Engine Combustion Concept SAE Technical Paper 2015-01-0788, 2015, doi:10.4271/201501-0788

16. Dolak, J., Shi, Y., and Reitz, R., A Computational Investigation of Stepped-Bowl Piston Geometry for a Light Duty Engine Operating at Low Load SAE Technical Paper 2010-01-1263, 2010, doi:10.4271/2010-01-1263.

17. Busch, S., F. Perini, and R.D. Reitz, Light-Duty Diesel Combustion, C.R.F. Sandia National Laboratories. 2016.

18. Chittick, S., M. Swindell, and S. Raorane, Analytical and Developmental Techniques Utilized in the Structural Optimization of a New Lightweight Diesel Engine. SAE International Journal of Engines, 2015. 8(4): p. 1960-1966.

19. Brettschneider, J., Berechnung des luftverhältnisses lambda von luft-kraftstoff-gemischen und des einflusses von messfehlern auf lambda. Bosch Tech. Ber., 1979. 6(4): p. 177-86.

20. AVL, Smoke value measurement with the filter paper method. Application notes, 2005.

21. British Standards, BS EN 590 Diesel, Requirements and Test Methods. 2009.

22. Richards, K.J., P.K. Senecal, and E. Pomraning, CONVERGE (v2.3). Convergent Science, 2016.

23. Colin, O. and A. Benkenida, The 3-zones extended coherent flame model (ECFM3Z) for computing premixed/diffusion combustion. Oil \& Gas Science and Technology, 2004. 59(6): p. 593-609.

24. Knop, V., J.-B. Michel, and O. Colin, On the use of a tabulation approach to model auto-ignition during flame propagation in SI engines. Applied energy, 2011. 88(12): p. 4968-4979.

25. Han, Z. and R.D. Reitz, Turbulence Modeling of Internal Combustion Engines Using RNG $\kappa-\varepsilon$ Models. Combustion Science and Technology, 1995. 106(4-6): p. 267-295.

26. Beale, J.C. and R.D. Reitz, Modeling spray atomization with the Kelvin-Helmholtz/Rayleigh-Taylor hybrid model. Atomization and sprays, 1999.9(6).

27. Amsden, A.A., P.J. O'Rourke, and T.D. Butler, KIVA-II: A computer program for chemically reactive flows with sprays, in Other Information: Portions of this document are illegible in microfiche products. 1989. p. Medium: X; Size: Pages: 164.

28. Schmidt, D.P. and C.J. Rutland, A New Droplet Collision Algorithm. Journal of Computational Physics, 2000. 164(1): p. 62-80.

29. Kuhnke, D., Spray/wall interaction modelling by dimensionless data analysis. 2004: Shaker.

30. Han, Z. and R.D. Reitz, A temperature wall function formulation for variable-density turbulent flows with application to engine convective heat transfer modeling. International Journal of Heat and Mass Transfer, 1997. 40(3): p. 613-625.

31. Bergin, M.J., et al., Examination of initialization and geometric details on the results of CFD simulations of diesel engines. Journal of Engineering for Gas Turbines and Power, 2011. 133(4): p. 044501.

\section{Contact Information}

Felix Leach,

Dept of Engineering Science

University of Oxford

Parks Rd

Oxford

OX1 3PJ

UK

felix.leach@eng.ox.ac.uk

\section{Acknowledgments}

The authors would like to thank Jaguar Land Rover Limited and University of Oxford John Fell fund for financial support. The authors would also like to thank BP International for supplying the Diesel. The authors would like to thank Liyah Dholiwar for undertaking much of the engine testing and the Dept of Engineering Science technicians and maintenance teams for facilities support. Riyaz Ismail would like to thank EPSRC for supporting his research. This paper is dedicated to the memory of Derek Pobgee, who put so much into the experimental facility at Oxford, who passed away in 2016.

\section{Definitions/Abbreviations}

CA b(a)TDC

Crank Angle before (after) Top Dead Centre

CA10

Angle of $10 \%$ mass fraction burned

CA50

Angle of 50\% mass fraction burned

CA90

Angle of $90 \%$ mass fraction burned

CFD

Computational Fluid Dynamics

DPF

Diesel Particulate Filter

EGR

Exhaust Gas Recirculation

IMEP

Indicated Mean Effective Pressure

ISFC

Indicated Specific Fuel

Consumption

ISNO $_{x}$

Indicated Specific Nitrogen Oxides

MFB

Mass Fraction Burned

$\mathrm{NO}_{\mathrm{x}}$

Nitrogen Oxides

NTP
Nozzle Tip Protrusion 
PM

Particulate Matter

Selective Catalytic Reduction

TDC

THC
Top Dead Centre

Total HydroCarbons
Ratio of actual Air Fuel Ratio to Stoichiometric Air Fuel Ratio

Page 10 of 10 